\title{
ASSESSMENT TRIBOLOGICAL PROPERTIES OF COATINGS APPLIED BY HVOF TECHNOLOGY
}

\author{
Janette BREZINOVÁ, Anna GUZANOVÁ*, Dagmar DRAGANOVSKÁ*, Marián EGRI ${ }^{*}$ \\ *Faculty of Mechanical Engineering, Department of Technology and Materials, Technical University of Košice, \\ Mäsiarska 74, 04001 Košice, Slovakia \\ **SLOVNAFT Montáže a Opravy, a.s., Vlčie hrdlo, P.O.Box 52, 82003 Bratislava, Slovakia \\ janette.brezinova@tuke.sk, anna.guzanova@tuke.sk, dagmar.draganovska@tuke.sk, marian.egri@slovnaft.sk
}

\begin{abstract}
In this article, the attention is paid to the HVOF (High Velocity Oxygen Fuel) thermal spraying method by which the progressive coatings are applied on basic material C15E (STN 412020). These coatings are based on C-17CO, WC-CO-Cr and Cr3C2-25NiCr. There was made determination of the chemical composition of the coatings and assessment of coatings quality - adhesion, microhardness, porosity and wear resistance at room temperature $\left(21^{\circ} \mathrm{C}\right)$ and also at operational elevated temperature $\left(900^{\circ} \mathrm{C}\right)$. Results of adhesive wear showed high quality of all evaluated coatings and their suitability to extreme tribological conditions.
\end{abstract}

Key words: HVOF Coatings, Adhesion, Hardness, Porosity, Wear Resistance

\section{INTRODUCTION}

The progressive coatings become an alternative for prospective application in various fields of industry because of their flexibility, high quality combined with durability in real and highly demanding conditions. Thermally-sprayed coatings belong to the dynamically developing field of surface engineering (Sahraoui et al., 2004; González-Hermosilla et al., 2010; Hadad et al., 2008; Fang, 2009; Bolelli, 2009). These high-quality functional coatings are applied in the basic industry, as well as in renovations (Tan et al., 1999), mainly due to their excellent properties, which are characterized by high wear resistance, corrosion resistance and resistance against high temperatures (Sahraoui et al., 2004 Ramesh et al., 2010; Boleli et al., 2007; Thakur et al., 2011I Lee et al., 2010; Maiti et al., 2007; Venkateswarlu et al., 2009). Thanks to wide range of different combinations coating-substrate material, thermal spraying offers as many possibilities as no other technology of coatings deposition. HVOF (High Velocity Oxygen Fuel) is one of the technology, which formed coatings with very small porosity (<1\%) compared with the basic material and high adhesion strength (> $80 \mathrm{MPa}$ ). There are minimal thermal changes of substrate during spraying and also roughness of coating surface is low. It is possible to deposit wide spectrum materials, from pure metals up to special alloys. Resistance of coating based on cermets is determined predominantly by type, morphology and size of hard particles and their volume fraction in a tough matrix.

The paper presents experimentally obtained results aimed at assessing selected coatings applied by HVOF technology: $\mathrm{C}-17 \mathrm{CO}$, WC-CO- $\mathrm{Cr}$ and $\mathrm{Cr}_{3} \mathrm{C}_{2}-25 \mathrm{NiCr}$. The coatings were subjected to couple of tests. Their tribological properties were evaluated by pin-on-disc test. The quality of coatings was evaluated by pull-off test, measuring the microhardness, and by EDX analysis. Conditions of experimental works were chosen in order to simulate operating conditions, namely wear in elevated temperature $\left(900^{\circ} \mathrm{C}\right)$.

\section{EXPERIMENTAL PROCEDURE}

Substrate for application the coatings was made of structural carbon steel C15E. Chemical composition of the steel is listed in Tab. 1.

Tab. 1. Chemical composition of the steel substrate (wt. \%)

\begin{tabular}{|c|c|c|c|c|}
\hline $\mathrm{C}$ & $\mathrm{Mn}$ & $\mathrm{Si}$ & $\mathrm{P}$ & $\mathrm{S}$ \\
\hline $0.12-0.18$ & $0.30-0.60$ & $0.15-0.40$ & $\max 0.035$ & $\max 0.035$ \\
\hline
\end{tabular}

Mechanical properties of the steel substrate: tensile strength $740-880 \mathrm{MPa}$, yield strength $\geq 440 \mathrm{MPa}$. The substrates for test samples were made from round bar $\varnothing 50 \mathrm{~mm}$ with a height of $15 \mathrm{~mm}$.

\section{Substrate pre-treatment}

Test samples were pre-treated by air grit blasting: air pressure of $0.5 \mathrm{MPa}$, abrasive - brown corundum, grain size $1.00 \mathrm{~mm}$. Material of coatings

There were deposited three types of coatings by HVOF technology on pretreated samples. On the first group of samples, coating of 1343 (C-17Co) was applied, on the second group of= samples coating of 1350 (WC-Co-Cr) was deposited and on the third group of samples coating $1375\left(\mathrm{Cr}_{3} \mathrm{C}_{2}-25 \mathrm{NiCr}\right)$ was deposited. Materials of coatings were supplied as a powder, agglomerated and sintered, produced by Praxair, Inc., USA. Tab. 2 shows chemical composition of the powders.

Tab. 2. Chemical composition of the powders sprayed

\begin{tabular}{|l|l|l|l|l|l|l|}
\hline Coating & C & Co & Fe & W & Cr & Ni \\
\hline 1343 & 5.5 & 16.2 & 0.036 & 78.4 & & \\
\hline 1350 & 5.5 & 9.9 & 0.02 & 80.6 & 3.9 & \\
\hline 1375 & 10 & & & & 68.5 & 21 \\
\hline
\end{tabular}

For the coating deposition equipment JP-5000, Praxair TA was used; it deposits coatings using system HP/HVOF (High 
Pressure/High Velocity Oxygen Fuel) with System Powder Feeder 1264. The surface of deposited coatings was not further modified after spraying. Parameters of spraying are listed in Tab. 3.

Tab. 3. Parameters of spraying and properties of coatings

\begin{tabular}{|l|c|}
\hline Particle velocity [m/s] & $600 \div 1000$ \\
\hline Adhesion [MPa] & $<70$ \\
\hline Oxide content [\%] & $1-2$ \\
\hline Porosity [\%] & $1-2$ \\
\hline Deposition power [kg/h] & $3-6$ \\
\hline Typical coating thickness [mm] & $0.2-2$ \\
\hline
\end{tabular}

\section{Testing of coatings properties}

Thickness of the coating was determined by magnetic thickness gauge. Construction, structure and chemical analysis of examined coatings was studied using scanning electron microscopy (SEM) JEOL JSM - $7000 \mathrm{~F}$. Chemical analysis was conducted using the EDX analyzer INCA, which allows local EDX chemical analysis of the material.To determine the basic properties of coatings, microhardness was measured according to STN ISO 4516 on Shimadzu HMV-2E test equipment, load 980,7 mN $(10 \mathrm{~g})$, dwell time $15 \mathrm{~s}$. Porosity of coatings was determined by mercury porosimetry using PoreMaster porosimeter. Adhesion of coatings was evaluated by pull-off test according to STN EN
582. After pull-off adhesion test, tensile stress necessary to rupture the weakest inter-phase (adhesive fracture) or the weaker component (cohesive fracture) were determined.

To simulate the working conditions, coatings were subjected to adhesive wear using pin-on-disc test (ISO 20808) at $21^{\circ} \mathrm{C}$ and $900^{\circ} \mathrm{C}$. Testing conditions: relative humidity $21 \%$, atmosphere: air, test ball diameter $ø 6 \mathrm{~mm}$, radius of ball track was $5.01 \mathrm{~mm}$, linear velocity $10.00 \mathrm{~cm} . \mathrm{s}-1$, normal load $5 \mathrm{~N}$, stop condition $300 \mathrm{~m}$.

\section{RESULTS AND DISCUSSION}

In Tab. 4 are presented values of thickness, microhardness and open porosity of evaluated coatings.

Tab. 4. Thickness, microhardness and total porosity of evaluated coatings

\begin{tabular}{|l|c|c|c|}
\hline Coating & 1343 & 1350 & 1375 \\
\hline Thickness [ $\mu \mathrm{m}]$ & 234 & 356 & 393 \\
\hline Microhardness HV0,1 & 1010 & 1447 & 975 \\
\hline Open porosity [\%] & 0.16 & 0.88 & 0.17 \\
\hline Adhesion [MPa] & 18.5 & 31.6 & 31.6 \\
\hline
\end{tabular}
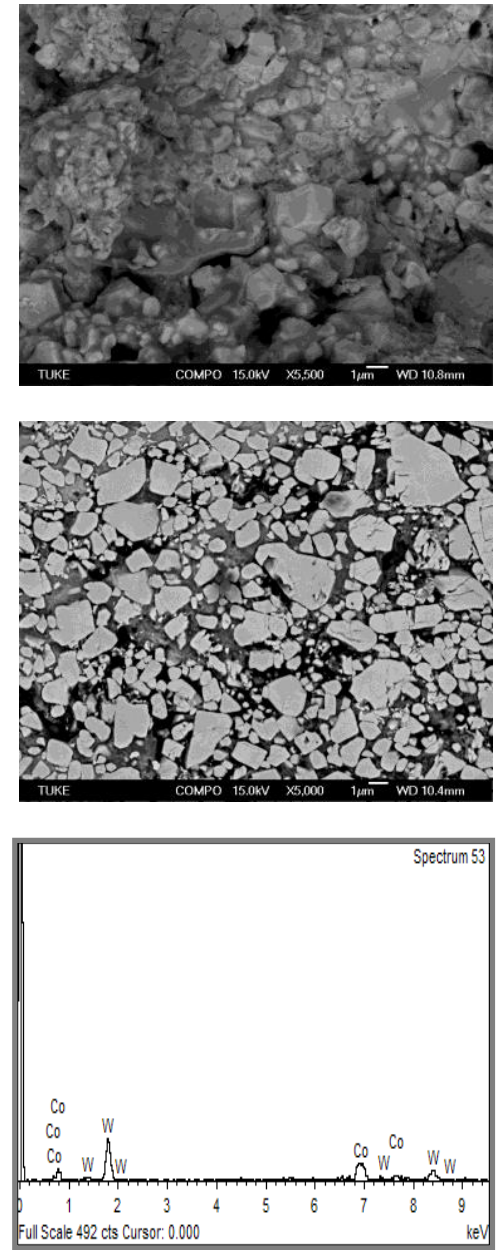

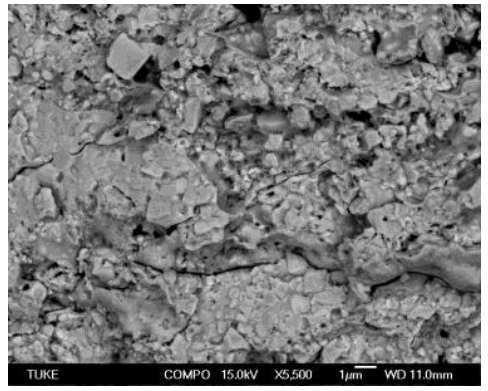

Fracture of coatings

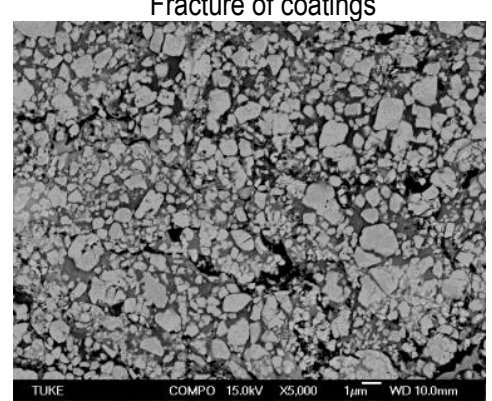

Cross-section of coatings

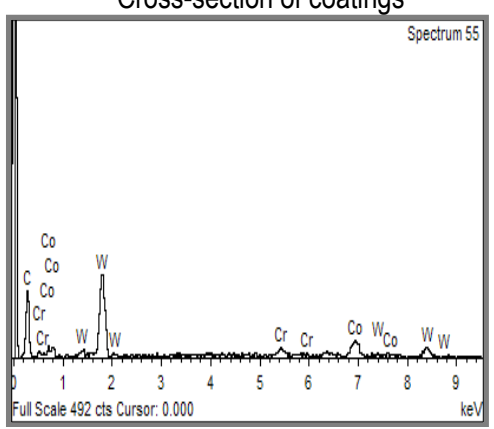

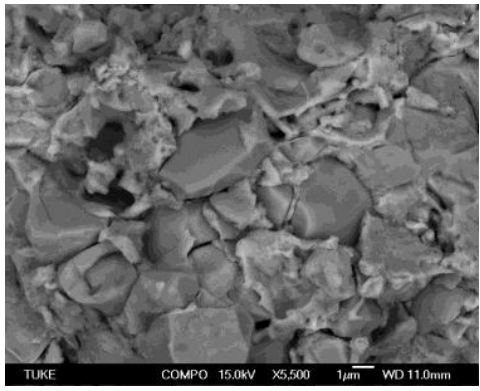
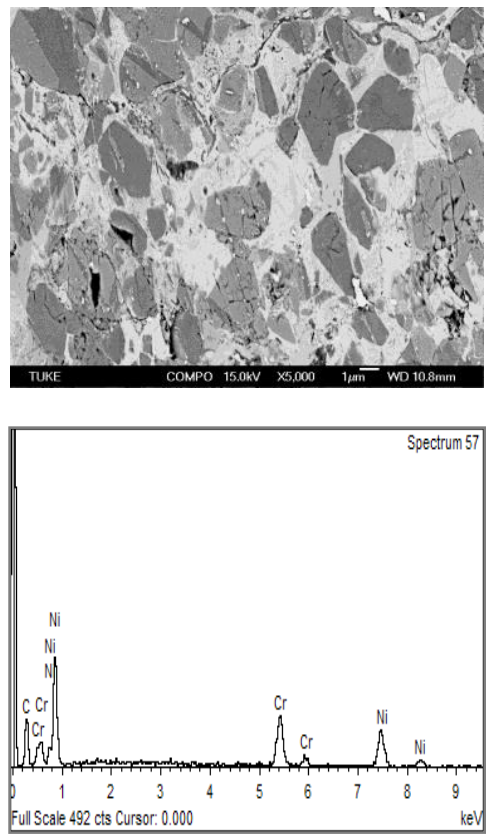

Fig. 1. Fractures, cross-sections and EDX analysis of coatings 
$21^{\circ} \mathrm{C}$

1343

1350

1375

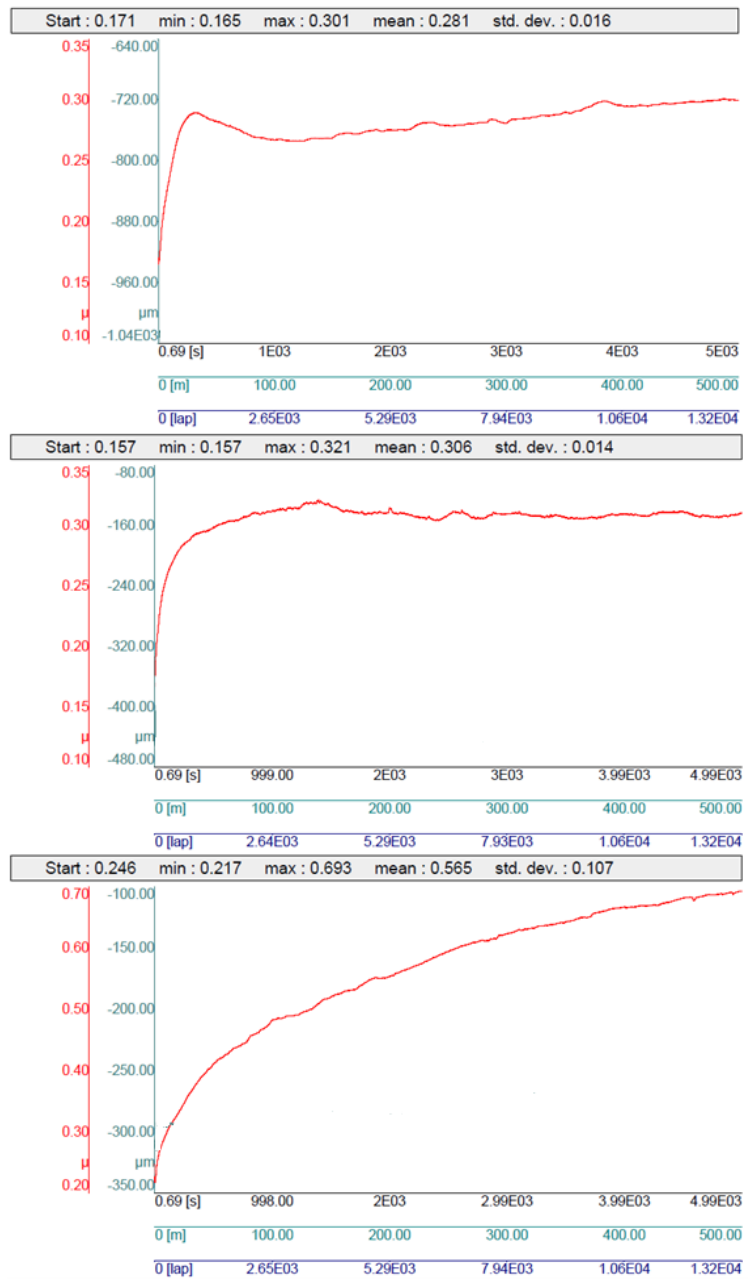

Fig. 2. Friction cefficient of coatings

Authors (Lee et al., 2009) stated porosity of coating 1350 (WC-Co-Cr) in the range of 0.6 to $2.7 \%$ depending on whether the powder is monodisperse or poly-disperse and on various portions of powder grain size in mixtures. Porosity was assessed by image analysis on cross-sections that included open and closed porosity together. Results of our research indicate that if we evaluate the porosity of the coating as a 3D body (in our case using mercury porosimetry), porosity of the coating is less $(0.88 \%)$, because the measure reflects only open pores.

Porosity of the coating $1375\left(\mathrm{Cr}_{3} \mathrm{C}_{2}-25 \mathrm{NiCr}\right)$ according the authors (Sidhu et al., 2006) is between 2.5-3.5 \% for the same reasons. Our research has confirmed the open porosity of the coating (1375) $0.17 \%$. The authors (Bolelli et al., 2009) who investigated the effect of the number of torch scans to the coating porosity have reached similar conclusions. It revealed that increasing thickness (number of torch scans) of coating lead to porosity decrease. However, they again found higher porosity on metallographic sections by image analysis than we by mercury porosimetry. Divergence of obtained porosity values results from different principle from the methods used.

The highest microhardness values was shown by coating 1350 (1447 HV 0,1) which was caused by a high content of tungsten and addition of cobalt compared to the coating 1343, which also contains tungsten but at lower concentrations and had lower values of microhardness $(1010 \mathrm{HV} 0,1)$. The lowest microhardness values were shown by coating 1375 with a high content $900^{\circ} \mathrm{C}$

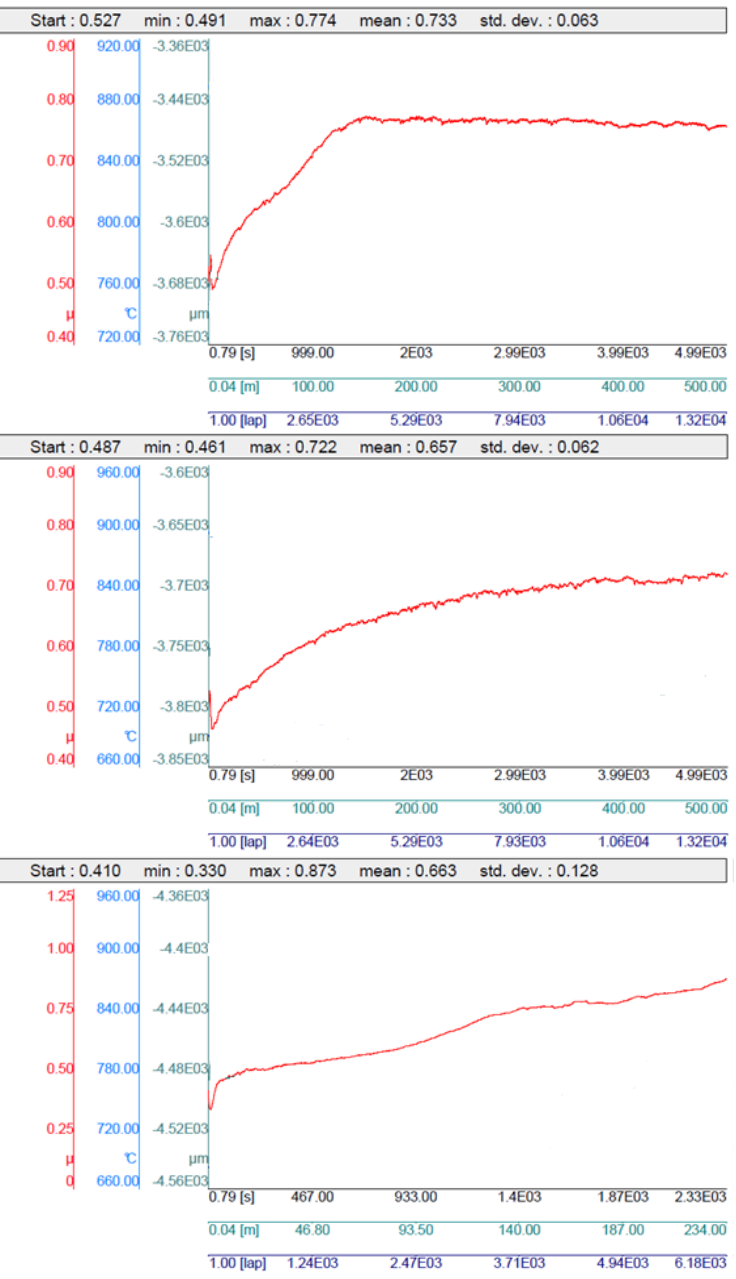

of chromium, tungsten-free (975 HV 0,1). The assessment of porosity showed that coating 1350 is more porous compared to the other two coatings which have almost the same porosity considering the structure of a coating and its chemical composition.

Coating 1343 reached a lower coating adhesion compared to coatings 1350 and 1375 . Fractures, cross-sections and results of EDX analysis are shown in Fig. 1.

EDX spectral analysis of the coating 1343 showed the presence of two basic phases - solid particles WC and cobalt surrounding WC particles, which corresponds to the chemical composition of powders for coatings production. EDX spectral analysis of the coating 1350 shows the presence of WC particles and chrome and cobalt matrix surrounding WC particles. EDX spectral analysis of the coating 1375 again confirmed the presence of large particles of $\mathrm{Cr}_{3} \mathrm{C}_{2}$ and the most extensive component of coating 1375 - nickel-chromium matrix. Matrix and hard particles of $\mathrm{WC}$ and $\mathrm{Cr}_{3} \mathrm{C}_{2}$ are well visible on cross-sections and also on fractures of the coatings.

The pin-on-disc test was realized at temperatures of the samples $20^{\circ} \mathrm{C}$ and $900^{\circ} \mathrm{C}$. Referred experiment temperature of $900^{\circ} \mathrm{C}$ was chosen because of simulation in real conditions in practice. It was evaluated and compared coefficient of friction [-], Fig. 2, the wear volume of disc specimen $V_{\text {disc }}\left[\mathrm{mm}^{3}\right]$ and specific wear rate of disc specimen $W\left[\mathrm{~mm}^{3} \cdot \mathrm{N}^{-1} \cdot \mathrm{m}^{-1}\right]$ at selected pressures and temperatures specified.

The coefficient of friction at $21^{\circ} \mathrm{C}$ was for the coating 1343 
and 1350 almost the same $(\sim 0.3 \pm 0.016)$, for the coating 1375 was more than twice and throughout the test continuously increased $(>0.7 \pm 0.107)$. At the test temperature $900^{\circ} \mathrm{C}$, all coatings achieved a considerably higher coefficient of friction than at room temperature. Fig. 3 shows wear traces of coatings.

After pin-on-disc test of all coatings at $21^{\circ} \mathrm{C}$ and $900^{\circ} \mathrm{C}$ were evaluated volume of material removal $\left(\mathrm{V}_{\text {disc }}\right)$ and the specific wear rate $\left(W_{\text {disc }}\right)$ from the depth profile of wear trace, Fig. 4.

Results of coatings wear test at $900^{\circ} \mathrm{C}$ showed that the wear rate of coatings 1343 and 1375 is extremely small, just a roughness change in wear track occured. The coating 1350 showed higher removal of material, $V_{\text {disc }, 900^{\circ} \mathrm{C}}=0.056 \mathrm{~mm}^{3}, \mathrm{~W}_{\mathrm{disc}, 900^{\circ} \mathrm{C}}=$ 3.7.10-5 $\mathrm{mm}^{3} \cdot \mathrm{N}^{-1} \cdot \mathrm{m}^{-1}$. For other coatings was not observed measurable weight loss of coating material. During the tribological tests the transfer of ball material to the surface of the tested coatings occured.

The authors (Bolelli et al., 2009) indicate wear reate of coating WC-Co-Cr (1350) at room temperature cca n.10-8 $\mathrm{mm}^{3} \cdot \mathrm{N}^{-1} \mathrm{~m}^{-1}$. Given the available weighing machine with a resolution of $10^{-5} \mathrm{~kg}$ weight we brand mass loss of evaluated coatings as unmeasurable (using our device), so we assumed mass loss below $10^{-5} \mathrm{~kg}$, which is consistent with the results of authors mentioned above. However, we also evaluated the wear rate at $900^{\circ} \mathrm{C}$, which were found higher wear rate of coating 1350: $3 \cdot 7 \cdot 10^{-5} \mathrm{~mm}^{3} \cdot \mathrm{N}^{-1} \cdot \mathrm{m}^{-1}$.
Results of adhesion test pointed on high quality of evaluated coatings and their suitability for extreme tribological conditions.

\section{CONCLUSIONS}

The paper discusses evaluation of selected properties of three types of cermet coatings applied by HVOF technology designed for high tribocorrosive conditions. The highest hardness showed coating WC-Co-Cr, which showed simultaneously the highest porosity.

This porosity was probably the cause of higher specific wear rate compared with other assessed coatings. Coatings C-17Co and $\mathrm{Cr} 3 \mathrm{C} 2-25 \mathrm{NiCr}$ despite of lower hardness achieved a higher resistance to the adhesive wear due to their chemical composition and structure of the coatings. In terms of frictional properties, the highest friction coefficient at $21^{\circ} \mathrm{C}$ showed coating $\mathrm{Cr} 3 \mathrm{C} 2-$ $25 \mathrm{NiCr}$, at $900^{\circ} \mathrm{C}$ a significant increasing in the friction coefficient for all coatings occured.

The results of experimental measurements showed that all investigated coatings, which showed a high quality and wear resistance, can be suggested to tribodegradation conditions at high temperatures.

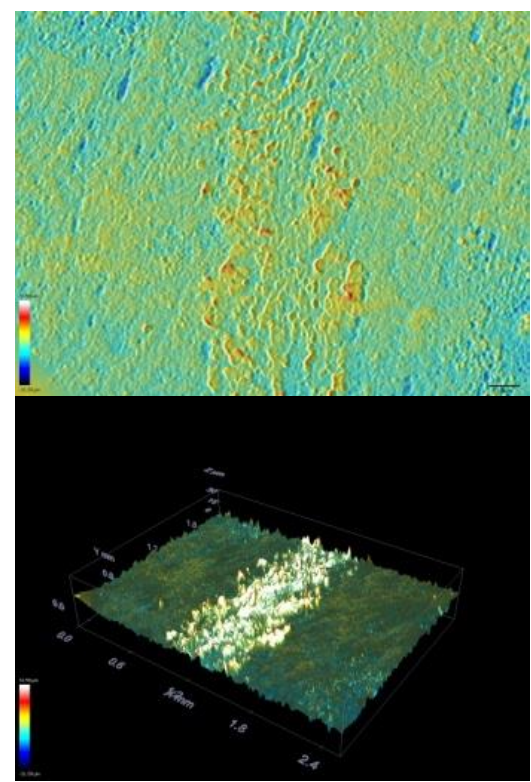

1343

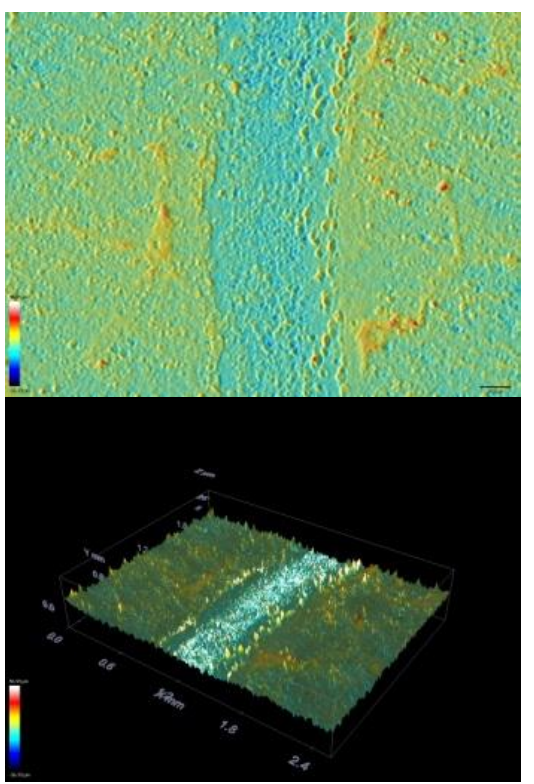

1350

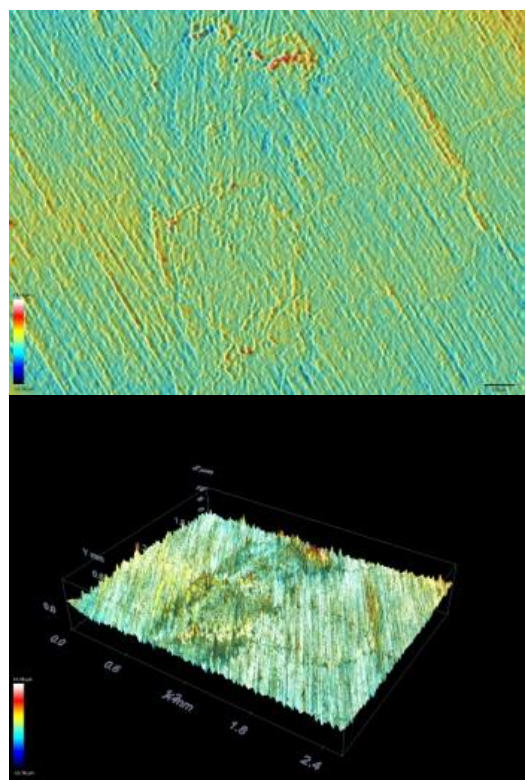

1375

Fig. 3 Wear traces of coatings

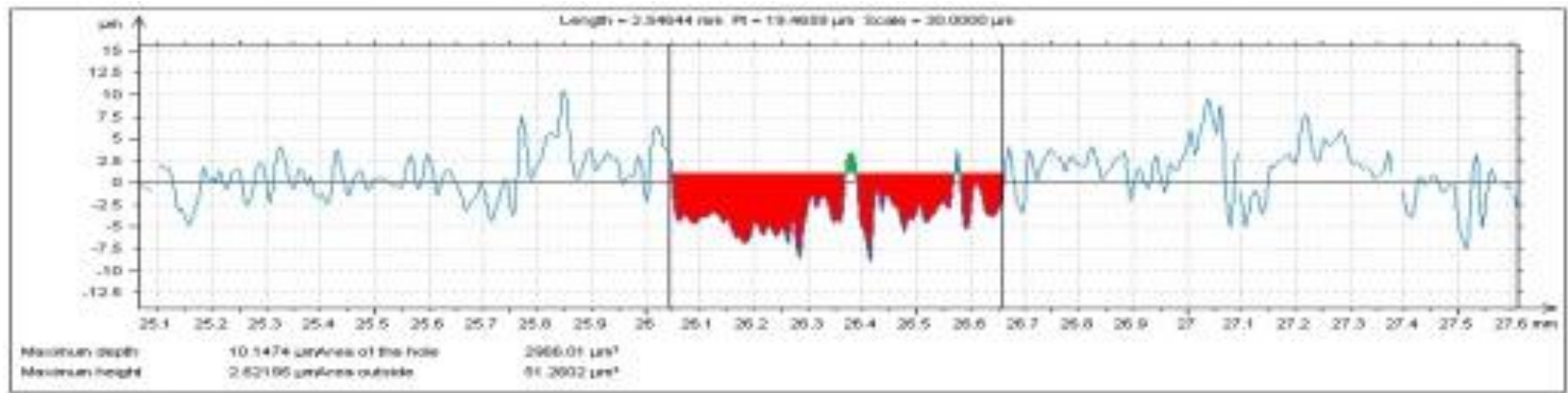

Fig. 4 Depth profile of coating 1350 wear trace 


\section{REFERENCES}

1. Bolelli G. (2009), HVOF-sprayedWC-CoCr coatings on Al alloy: Effect of the coating thickness on the tribological properties, Wear, Vol. 267, 944-953.

2. Bolelli G. et al. (2007), Microstructural and tribological comparison of HVOF-sprayed and post-treated M-Mo-Cr-Si (M=Co, Ni) alloy coatings, Wear, Vol. 263, 1397-1416.

3. Bolelli G., Lusvarghi L., Barletta M. (2009), HVOF-sprayedWCCoCr coatings on Al alloy: Effect of the coating thickness on the tribological properties, Wear, Vol. 267, 944-953.

4. Fang W. (2009), Processing optimization, surface properties and wear behavior of HVOF spraying WC-CrC-Ni coating, Journal of Materials Processing Technology, Vol. 209, 3561-3567.

5. González-Hermosilla W. A. et al. (2010), Effect of substrate roughness on the fatigue behavior of a SAE 1045 steel coated with a WC-10Co-4Cr cermet, deposited by HVOF thermal spray, Materials Science and Engineering A, Vol. 527, 6551-6561.

6. Hadad M. et al. (2008), Adhesion evaluation of multilayered based WC-Co-Cr thermally sprayed coatings, Surface and Coatings Technology, Vol. 202, 4399-4405

7. Lee C.W., Han J.H., Yoon J., Shin M.C., Kwun S.I. (2010), A study on powder mixing for high fracture toughness and wear resistance of WC-Co-Cr coatings sprayed by HVOF, Surface and Coatings Technology, Vol. 204, 2223-2229.

8. Lee C.W., Han J.H., Yoon J., Shin M.C., Kwun S.I. (2010), A study on powder mixing for high fracture toughness and wear resistance of WC-Co-Cr coatings sprayed by HVOF, Surface and Coatings Technology, Vol. 204, 2223-2229.
9. Maiti A.K., Mukhopadhyay N., Raman R. (2007), Effect of adding WC powder to the feedstock of WC-Co-Cr based HVOF coating and its impact on erosion and abrasion resistance, Surface and Coatings Technology, Vol. 201, 7781-7788.

10. Ramesh M.R. et al. (2010), Solid particle erosion of HVOF sprayed WC-Co/NiCrFeSiB coatings, Wear, Vol. 269 197-205.

11. Sahraoui T., Guessasma S., Fenineche N. E., Montavon G. Coddet C. (2004), Friction and wear behaviour prediction of HVOF coatings and electroplated hard chromium using neural computation, Materials Letters, Vol. 58, 654-660.

12. Sidhu H. S., Sidhu B. S., Prakash S. (2006), Mechanical and microstructural properties of HVOF sprayed WC-Co and $\mathrm{Cr}_{3} \mathrm{C}_{2}-\mathrm{NiCr}$ coatings on the boiler tube steels using LPG as the fuel gas, Journal of Materials Processing Technology, Vol. 171, 77-82.

13. Tan J.C., Looney L., Hashmi M.S.J. (1999), Component repair using HVOF thermal spraying, Journal of Materials Processing Technology, Vol. 92-93, 203-208.

14. Thakur L., Arora N., Jayaganthan R., Sood R. (2011), An investigation on erosion behavior of HVOF sprayed $\mathrm{WC}-\mathrm{CoCr}$ coatings, Applied Surface Science, Vol. 258 1225-1234.

15. Venkateswarlu K. et al. (2009), Abrasive wear behavior of thermally sprayed diamond reinforced composite coating deposited with both oxy-acetylene and HVOF techniques, Wear, Vol. 266, 996-1002.

This contribution was supported by Grant Agency VEGA No. 1/0600/13 The authors are grateful to APVV for support of experimental work under grant APVV-0682-11 - Application of progressive tool coatings for increasing the effectiveness and productivity of forming sheets made of modern materials. 